\title{
Characterization and resistance pattern of bacterial isolates from pus samples in a tertiary care hospital, Karimnagar
}

\author{
Krishnamurthy $\mathbf{S}^{1}$, Sajjan $\mathrm{AC}^{2}$, G. Swetha ${ }^{3}$, S Shalini ${ }^{4}$ \\ ${ }^{1}$ Dr Krishnamurthy Sirigadha, Professor and HOD, ${ }^{2}$ Dr Amar C Sajjan, Assistant professor, ${ }^{3}$ Ms Swetha, MSc Medical \\ Microbiology, ${ }^{4}$ Dr Shalini S, Post graduate, all authors are affiliated with Department of Microbiology, Chalmeda Anand \\ Rao Institute of Medical Sciences, Karimnagar, Telangana, India.
}

Address for Correspondence: Dr Amar C Sajjan, Chalmeda Anand Rao Institute of Medical Sciences, Staff Quarters, Block-B; NO-304, Bommakal, Karimnagar, Telangana. E-mail id: dr.amarcs@gmail.com

\begin{abstract}
Background: Wound infection can cause delayed healing, chronicity which indirectly causes financial burden and psychological stress on patients. Aim: To speciate the organism isolated from pus sample received and its antibiotic sensitivity test. Methods and materials: All isolated organism are identified by colony morphology, Gram stain and biochemical reactions. Antibiotic sensitivity test for all isolates were done by Kirby-Bauer method using Mueller Hinton agar. Results: The major contribution of sample was from surgery department $(65.3 \%)$ followed by orthopedics (10.2\%). A total of 383 organism isolated among which Klebsiella pneumoniae dominates $(34.46 \%)$ followed by Staphylococcus aureus (18.53\%). All Gram negative organisms showed maximum resistance to amoxyclav and least to Imipenem. All Gram positive organisms showed least resistance to Vancomycin and Linezolid. Pseudomonas aeruginosa showed maximum resistance to amoxyclav (66.1\%) and Gentamicin (57.1\%) and least to Imipenem (7.1\%). Conclusion: It is observed from the present study that, there is an increase in the resistance among beta-lactam antibiotics and quinolones. Emergence of drug resistance can be effectively controlled by continuous surveillance in hospitals and rational use of antibiotics.
\end{abstract}

Key words: Pus, Antibiotic resistance, Methicillin-resistant Staphylococcus aureus (MRSA), Wound infections.

\section{Introduction}

Wound infections are associated with higher rate of morbidity, mortality and increased medical expenses. Surgical wound infections are second most common cause of wound infections [1,2]. Treating wound infection mainly depends upon understanding of causative pathogen, pathophysiology of infective process and pharmacokinetics of drugs used for treatment [3]. There is increase in the development of resistance especially in developing countries due to indiscriminate use of antibiotics [4]. Bacteria have the ability to acquire resistance to therapeutic drugs and can transfer the resistance from one bacteria to another [5].

This study is conducted to know the prevalence of bacterial isolates from pus samples and its antibiotic sensitivity pattern which guides for appropriate therapy and framing antibiotic policies for hospital.

Manuscript received: $14^{\text {th }}$ July 2016

Reviewed: $25^{\text {th }}$ July 2016

Author Corrected: $10^{\text {th }}$ August 2016

Accepted for Publication: $24^{\text {th }}$ August 2016

\section{Methods and Materials}

Study design and duration: This is a retrospective study conducted for 2 years that is from July 2014 to June 2016.

Statistical analysis: The results were analysed using pivot table in MS office excel 2007. The present study conducted in a tertiary care hospital, Karimnagar. The pus samples received to laboratory from patients attending hospital were collected with sterile disposable cotton swabs and aspirates in syringe were processed. Among two pus swabs received, one swab used for direct Gram staining and another for inoculating on Blood agar (BA), MacConkey agar (MA) and Nutrient agar (NA). Culture plates were incubated at $37^{0} \mathrm{C}$ for 24 to 48 hours. Organism isolated identified by colony morphology, Gram stain, catalase test, oxidase test, coagulase test and other biochemical tests. Antibiotic sensitivity test for all isolates were done by KirbyBauer method using Mueller Hinton agar [6,7]. 


\section{Results}

Of total population $64 \%$ were male.

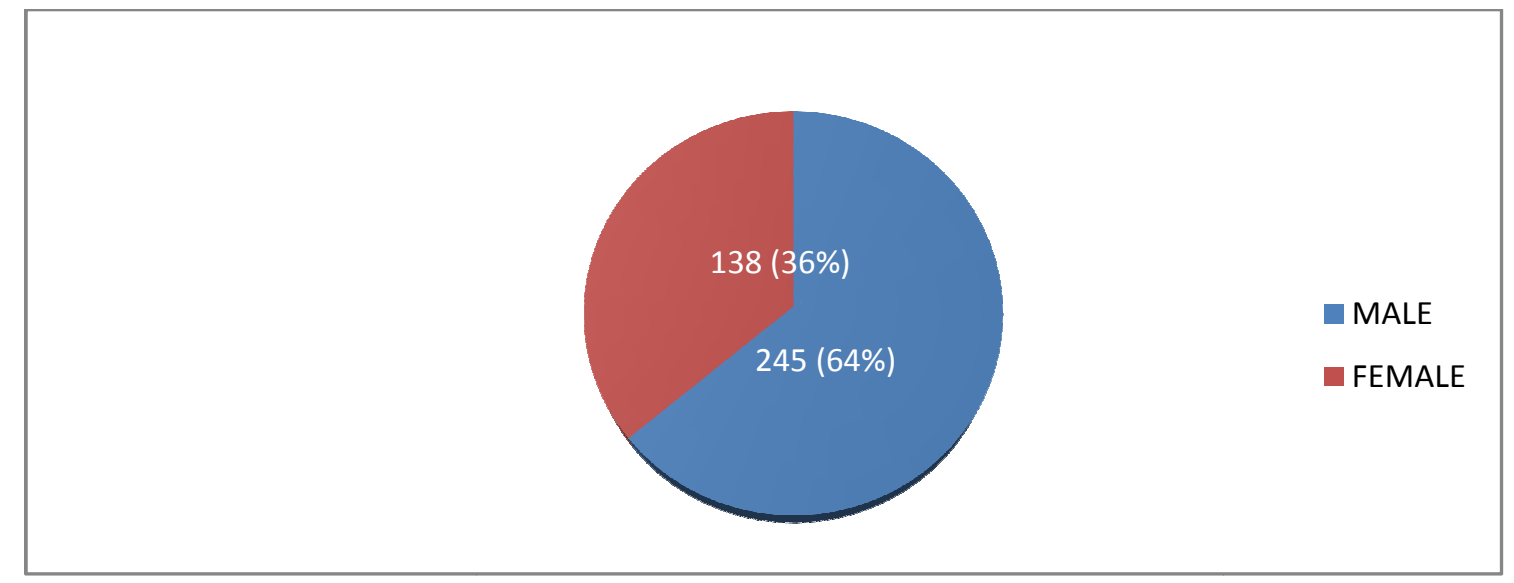

Figure-1: Sex wise distribution of culture positive pus samples

Table-1: Age wise distribution of bacterial isolates from pus samples.

\begin{tabular}{|c|c|c|c|c|c|c|c|}
\hline Age range & $\begin{array}{c}\text { K. } \\
\text { pneumoniae }\end{array}$ & S. aureus & E. coli & Pseudomonas & CONS & others & $\begin{array}{c}\text { Grand } \\
\text { Total }\end{array}$ \\
\hline $1<$ & 1 & 1 & & 2 & 3 & & 7 \\
\hline $2-21$ & 13 & 16 & 9 & 8 & 10 & & 56 \\
\hline $22-41$ & 42 & 24 & 17 & 14 & 17 & 2 & 116 \\
\hline $42-61$ & 38 & 17 & 22 & 19 & 7 & 3 & 106 \\
\hline $62-81$ & 36 & 10 & 15 & 13 & 9 & 7 & 91 \\
\hline $82-101$ & 2 & 3 & 1 & & 1 & & 7 \\
\hline & $\mathbf{1 3 2}$ & $\mathbf{7 1}$ & $\mathbf{6 4}$ & $\mathbf{5 7}$ & $\mathbf{4 7}$ & $\mathbf{1 2}$ & $\mathbf{3 8 3}$ \\
\hline
\end{tabular}

Frequency of bacterial isolation was maximum among age group 22 to 41 years followed by 42 to 61 years

Table-2: Department wise distribution of bacterial isolates from pus samples.

\begin{tabular}{|c|c|c|c|c|c|c|c|c|}
\hline \multirow{2}{*}{ Organism } & \multicolumn{9}{|c|}{ Departments } \\
\cline { 2 - 9 } & Surgery & Orthopedics & OBG & ICU & ENT & GM & NICU & OTHERS \\
\hline $\begin{array}{c}\text { Klebsiella } \\
\text { pneumoniae }\end{array}$ & 92 & 6 & 8 & 8 & 5 & 4 & 1 & 8 \\
\hline S.aureus & 41 & 20 & 1 & 2 & 1 & 2 & 1 & 3 \\
\hline E. coli & 43 & 1 & 12 & 3 & 0 & 0 & 0 & 5 \\
\hline $\begin{array}{c}\text { Pseudomonas } \\
\text { aeruginosa }\end{array}$ & 40 & 5 & 1 & 0 & 4 & 1 & 2 & 3 \\
\hline CONS & 25 & 7 & 7 & 2 & 0 & 1 & 3 & 2 \\
\hline Others & 10 & 0 & 1 & 0 & 0 & 0 & 0 & 1 \\
\hline
\end{tabular}

A total of 383 culture positive pus samples which includes swabs and aspirates were processed. The major contribution of sample was from surgery department $(65.3 \%)$ followed by orthopaedics (10.2), OBG (7.8\%), ICU (4.2\%), General medicine $(2.3 \%)$, ENT (2.6\%), NICU (1.8\%) and other department $(5.7 \%)$ which include, neurosurgery, cardiology, urology, oncology

A total of 383 organism isolated among which Klebsiella pneumoniae dominates (34.46\%) followed by Staphylococcus aureus (18.53\%), Escherichia coli (16.2\%), Pseudomonas aeruginosa (14.6\%), CONS (12.3\%) and other organisms which include Proteus sp, Klebsiella oxytoca, Acinetobacter baumannii. 
Research Article

Table-3: Antibiotic sensitivity pattern of Staphylococcus aureus.

\begin{tabular}{|c|c|c|c|c|}
\hline Organisms & \multicolumn{3}{|c|}{ Staphylococcus aureus ( $\mathrm{n}=71)$} \\
\hline & \multicolumn{2}{|c|}{ Sensitive } & Resistance \\
\hline Antibiotics & Number & Percentage & 7 & $9.9 \%$ \\
\hline Amikacin & 64 & $90.1 \%$ & 38 & $53.5 \%$ \\
\hline Amoxyclav & 33 & $46.5 \%$ & 27 & $38 \%$ \\
\hline Azithromycin & 44 & $62 \%$ & 29 & $39.8 \%$ \\
\hline Cefotaxime & 42 & $59.2 \%$ & 28 & $1.5 \%$ \\
\hline Ceftriaxone & 43 & $60.6 \%$ & 1 & $46.5 \%$ \\
\hline Linezolid & 70 & $98.5 \%$ & 33 & $18.3 \%$ \\
\hline Ofloxacin & 38 & $53.5 \%$ & 3 & $4.2 \%$ \\
\hline Pipercillin/ Tazobactam & 58 & $81.7 \%$ & 26 & $36.6 \%$ \\
\hline Vancomycin & 68 & $95.8 \%$ & $63.4 \%$ & \\
\hline Cefoxitin & 45 & & & 39.4 \\
\hline
\end{tabular}

Staphylococcus aureus showing maximum resistance to Amoxyclav (53.5\%) followed by Ofloxacin (46.5\%), Cefotaxime $(40.8 \%)$ and least to Vancomycin (4.2\%), Linezolid (1.5\%).

Table-4: Antibiotic sensitivity pattern of CONS (Coagulase Negative Staphylococcus).

\begin{tabular}{|c|c|c|c|c|}
\hline Organism & \multicolumn{3}{|c|}{ CONS (n=47) } \\
\hline & \multicolumn{2}{|c|}{ Sensitive } & Resistance \\
\hline Antibiotics & Number & Percentage & 12 & $25.5 \%$ \\
\hline Amikacin & 35 & $74.5 \%$ & 21 & $44.7 \%$ \\
\hline Amoxyclav & 26 & $55.3 \%$ & 22 & $46.8 \%$ \\
\hline Cefotaxime & 25 & $53.2 \%$ & 23 & $48.9 \%$ \\
\hline Ceftriaxone & 24 & $51.1 \%$ & 0 & 0 \\
\hline Linezolid & 47 & $100 \%$ & 22 & $46.8 \%$ \\
\hline Ofloxacin & 25 & $53.2 \%$ & 14 & $29.8 \%$ \\
\hline Pipercillin/ Tazobactam & 33 & $70.2 \%$ & 1 & $2.3 \%$ \\
\hline Vancomycin & 46 & $97.7 \%$ & & \\
\hline
\end{tabular}

CONS showing maximum resistance to Ceftriaxone (48.9\%), Cefotaxime (46.8\%), Ofloxacin (46.8\%), Amoxyclav (44.7\%), followed by Pipercillin/ Tazobactam (29.8\%). All isolates were sensitive to Linezolid and only one isolate showed resistance to Vancomycin.

Table-5: Antibiotic sensitivity pattern of Escherichia coli.

\begin{tabular}{|c|c|c|c|c|}
\hline & \multicolumn{3}{|c|}{ Escherichia coli (n=64) } \\
\hline & \multicolumn{2}{|c|}{ Sensitive } & \multicolumn{2}{c|}{ Resistance } \\
\hline Antibiotics & Number & Percentage & Number & $17.2 \%$ \\
\hline Amikacin & 53 & $82.8 \%$ & 11 & $89.1 \%$ \\
\hline Amoxyclav & 7 & $10.9 \%$ & 57 & $79.7 \%$ \\
\hline Cefotaxime & 13 & $20.3 \%$ & 51 & $1.5 \%$ \\
\hline Ceftriaxone & 7 & $10.9 \%$ & 57 & $51.6 \%$ \\
\hline Imipenum & 63 & $98.5 \%$ & 1 & $23.4 \%$ \\
\hline Ofloxacin & 31 & $48.4 \%$ & 33 & 15 \\
\hline Pipercillin/ Tazobactam & 49 & $76.6 \%$ & & $89.1 \%$ \\
\hline
\end{tabular}

Both Amoxyclav and Ceftriaxone showing maximum resistance with $89.1 \%$, followed by Cefotaxime $(79.7 \%)$. Only one isolate showing resistance to Imipenum. 
Research Article

Table-6: Antibiotic pattern of Klebsiella pneumoniae.

\begin{tabular}{|c|c|c|c|c|}
\hline Organism & \multicolumn{4}{|c|}{ Klebsiella pneumoniae $(n=132)$} \\
\hline & \multicolumn{2}{|c|}{ Sensitive } & \multicolumn{2}{|c|}{ Resistance } \\
\hline Antibiotics & Number & Percentage & Number & Percentage \\
\hline Amikacin & 96 & $72.7 \%$ & 36 & $27.3 \%$ \\
\hline Amoxyclav & 12 & $9.1 \%$ & 120 & $90.9 \%$ \\
\hline Cefotaxime & 28 & $21.2 \%$ & 104 & $78.8 \%$ \\
\hline Ceftriaxone & 30 & $27.7 \%$ & 102 & $72.3 \%$ \\
\hline Imipenum & 124 & $93.9 \%$ & 8 & $6.1 \%$ \\
\hline Ofloxacin & 83 & $62.9 \%$ & 49 & $37.1 \%$ \\
\hline Pipercillin/ Tazobactam & 71 & $53.8 \%$ & 61 & $46.2 \%$ \\
\hline
\end{tabular}

Among enterobacteriaceae, Klebsiella pneumoniae showing maximum resistance among amoxyclav (90.9\%), Cefotaxime (78.8\%), Ceftriaxone (72.3\%) and Imipenum $(6.1 \%)$

Table-7: Antibiotic sensitivity pattern of Pseudomonas aeruginosa.

\begin{tabular}{|c|c|c|c|c|}
\hline \multirow{2}{*}{ Organism } & \multicolumn{3}{|c|}{ Pseudomonas aeruginosa (n=56) } \\
\hline & \multicolumn{2}{|c|}{ Sensitive } & Rumber & Percentage \\
\hline Antibiotics & Number & Percentage & 15 & $26.8 \%$ \\
\hline Amikacin & 41 & $73.5 \%$ & 37 & $66.1 \%$ \\
\hline Amoxyclav & 19 & $33.9 \%$ & 16 & $28.6 \%$ \\
\hline Carbencillin & 40 & $71.4 \%$ & 35 & $62.5 \%$ \\
\hline Cefotaxime & 21 & $37.5 \%$ & 33 & $58.9 \%$ \\
\hline Ceftriaxone & 23 & $41.1 \%$ & 32 & $57.1 \%$ \\
\hline Gentamycin & 24 & $42.9 \%$ & 4 & $3.1 \%$ \\
\hline Imipenum & 52 & $92.9 \%$ & 22 & $39.3 \%$ \\
\hline Ofloxacin & 34 & $60.7 \%$ & 21 & $37.5 \%$ \\
\hline Pipercillin/ Tazobactam & 35 & $62.5 \%$ & & \\
\hline
\end{tabular}

Like other Gram negative organism, Pseudomonas aeruginosa showing maximum sensitive to imipenum( $(92.9 \%)$ and least sensitive to Amoxyclav.

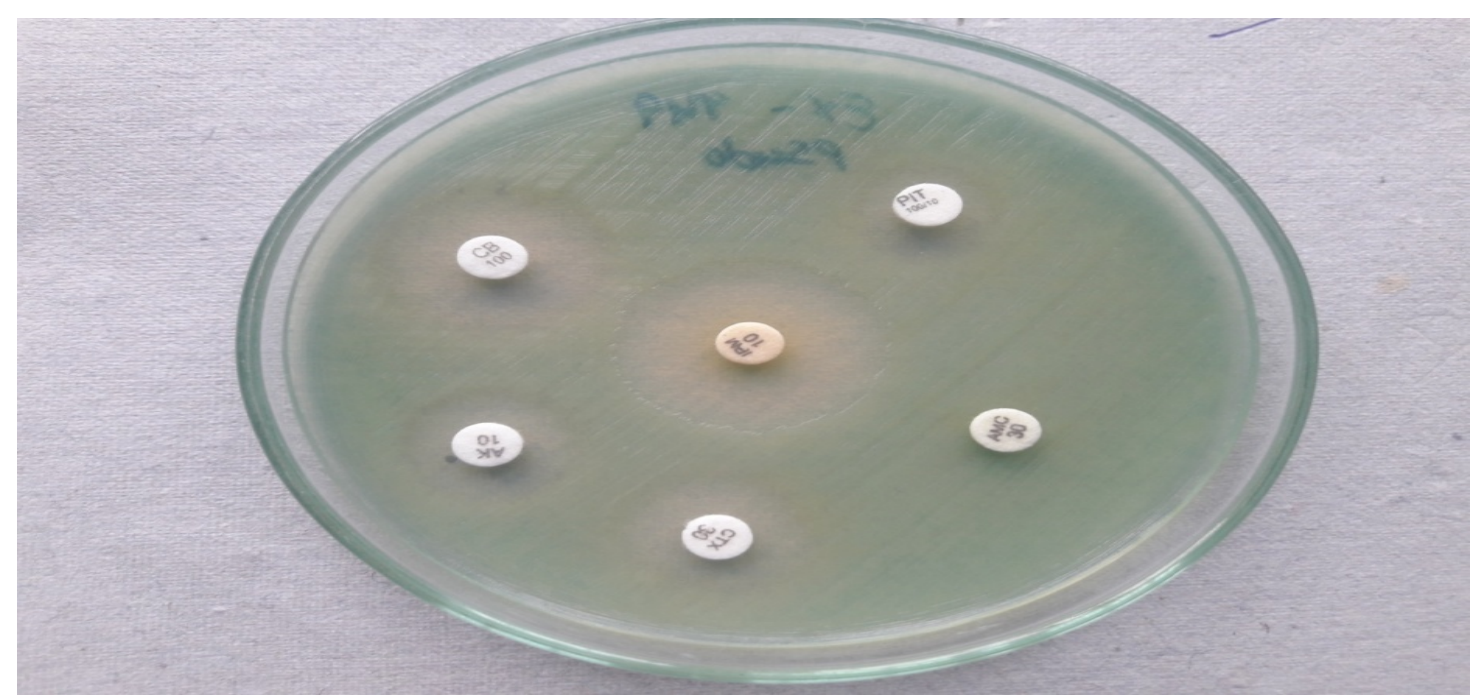

Figure-2: Antibiotic sensitivity test on Mueller Hinton agar by Kirby-Beaur method 


\section{Discussion}

In this study there is male predominance and majority of patients are in age group 20-40 followed by 40-60 which is seen in previous study [1].

In present study Staphylococcus aureus is the predominant organism among Gram positive organisms which is comparable with many studies $[4,8,9]$. Among CONS, Staphylococcus epidermidis predominates followed by Staphylococcus saprophyticus which is in according with study conducted by Mohan U at al [10].

Klebsiella pneumonia is predominant organism isolated in our study with similar findings shown in studies by Sharma V et al [11] and Panta K et al [12], but in the study conducted by Kumar AR et al [4] and Verma P et al [13] it was second most common isolate.

Resistance pattern of $S$. aureus as seen in table 7 shows maximum resistance to amoxyclav $(53.5 \%)$ followed by Ofloxacin $(46.5 \%)$. Resistance for third generation cephalosporin like Cefotaxime and Ceftriaxone differ by narrow percentage with 40.5 and 39.4 respectively which is similar to study done at Jodhpur by Duggal $\mathrm{S}$ at al [14].

MRSA testing of $S$. aureus was done using Cefoxitin $(30 \mu \mathrm{g})$ which showed $36.6 \%$ which is similar to other studies $[9,15]$. Vancomycin and Linezolid showed $4.2 \%$ and $1.5 \%$ resistance for $S$. aureus but some studies showed $8 \%$ and $4 \%$ respectively [14]. A study in Iran by sarraafzadeh $\mathrm{F}$ et al [16] reported $9.2 \%$ resistance for Vancomycin and some showed $100 \%$ sensitive [9].

Escherichia coli and Klebsiella pneumoniae showed highest resistance to amoxyclav which is $89.1 \%$ and 90.9\% respectively. Separate table is made for Klebsiella pneumoniae since it is gaining importance because of emerging multidrug resistance. In current study it is observed that Klebsiella pneumoniae showing resistance to Imipenem and Pipercillin/ Tazobactam of $6.1 \%$ and $46.2 \%$ where as Escherichia coli showed only $1.5 \%$ and $23.4 \%$ resistance respectively. Similar resistance pattern was reported by Namratha KG et al [17].

Here in our present study Pseudomonas aeruginosa showed prevalence of about $14.6 \%$.

Various studies showed prevalence between $15 \%$ to $42 \%[1,3,8,9,11,14,18]$.
Pseudomonas aeruginosa encountered maximum resistance to amoxyclav $(66.1 \%)$ and least to Imipenem $(7.1 \%)$. Gentamicin resistance was $57.1 \%$ which is in accordance with work done by Hosimin K et al [19] which showed $50 \%$ resistance. Least resistance to Imipenem was reported by Duggal S at al [14] which is similar to our present study but same study showed Ofloxacin resistance of $72 \%$ where as in our study it is only $39.3 \%$.

\section{Conclusion}

The present study showed alarming increase in the resistance to amoxyclav and third generation cephalosporins for all the isolates which is a serious problem in local area. To combat this we strongly advocate for rational use of antibiotics.

Acknowledgment: I thank Dr Rani Padmavathi for assisting in tabulating results and writing the article.

Funding: Nil, Conflict of interest: None initiated, Permission from IRB: Yes

\section{References}

1. Sawdekar H, Sawdekar R, Wasnik VR. Antimicrobial susceptibility pattern of bacterial isolates from wound infection and their sensitivity to antibiotic agents at super specialty hospital, Amravati city, India. Int J Res Med Sci. 2015; 3(2): 433-439. doi: 10. 5455/2320-6012.ijrms20150210.

2. Burke JP. Infection control - a problem for patient safety. N Engl J Med. 2003 Feb 13;348(7):651-6.

3. Sowmya N, Savitha S, Mallure S, Mohanakrishnan SK, Sumathi S et al. Two year study of spectrum of bacterial isolates from wound infections by aerobic culture and their antibiotic pattern in a tertiary care center. Int.J.Curr.Microbiol.App.Sci .2014; 3(8): 292295.

4. Kumar AR. Antimicrobial sensitivity pattern of Klebsiella pneumonia isolated from pus from tertiary care hospital and issues related to the rational selection of antimicrobials. J. Chem. Pharm. Res, 2013; 5(11): 326-331.

5. Jaiswal S, Pandey R, Sharma B. Reduction of antibiotic resistance in bacteria: a review., IJPSR. 2012; 3(1): $695-699$. 


\section{Research Article}

6. Colle JG, Duguid JP, Fraser AG, Marmion BP, Simmons A. Laboratory strategy in the diagnosis of infective syndromes. In: Colle JG, Fraser AG, Marmion BP, Simmons A, editors. Mackie and McCartneyPractical Medical Microbiology. 14th ed. New Delhi: Elsevier; 2006; 68-69.

7. CLSI. Performance Standards for Antimicrobial Susceptibility Testing; Twenty-Fifth Informational Supplement. CLSI document M100-S25. Wayne, PA: Clinical and Laboratory Standards Institute; 2015.

8. Bessa LJ, Fazii P, Di Giulio M, Cellini L. Bacterial isolates from infected wounds and their antibiotic susceptibility pattern: some remarks about wound infection. Int Wound J. 2015 Feb;12(1):47-52. doi: 10.1111/iwj.12049. Epub 2013 Feb 24.

9. Sangwan J, Singla P, Mane P, Lathwal S, Malik AK. Prevalence and antimicrobial susceptibility patterns of aerobic bacterial isolates from pyogenic wound infections at a tertiary care institute in Haryana, India. Int.J.Curr.Microbiol.App.Sci. 2016; 5(2): 78-85. doi: http://dx.doi.org/10.20546/ijcmas.2016.502.008.

10. Mohan U, Jindal N, Aggarwal P. Species distribution and antibiotic sensitivity pattern of coagulase negative staphylococci isolated from various clinical specimens. Indian J Med Microbiol. 2002; $20: 45-6$

11. Sharma V, Parihar G, Sharma V, Sharma H. A Study of Various Isolates from Pus Sample with Their Antibiogram from Jln Hospital, Ajmer. Journal of dental and medical sciences. 2015 Oct;14(10),Ver. VI:64-68. doi: 10.9790/0853-141066468.

12. Panta K, Ghimire P, Rai SK, Mukhiya RK, Singh RN, Ganesh Rai. Antibiogram typing of gram negative isolates in different clinical samples of a tertiary hospital. Asian Journal of Pharmaceutical and Clinical Research.2013;6(1):153-156.

13. Verma P. A study on isolation of different type of bacteria from pus. Int $\mathbf{J}$ of Pharm Life Sci.2012 Nov;3(11): 2107-2110.

14. Duggal S, Khatri PK, Parihar RS, Arora R. Antibiogram of various bacterial isolates from pus samples in a tertiary care centre in Rajasthan. International Journal of Science and Research. 2015 May;4(5):1580-1584.

15. Joshi S, Ray P, Manchanda V, Bajaj J, Chitnis DS, Gautam V. Methicillin resistant Staphylococcus aureus (MRSA) in India: Prevalence \& susceptibility pattern. Indian J Med Res. 2013 Feb; 137:363-369.

16. Sarrafzadeh F, Mirzabiegi Z, Nami MT. Vancomycin-Resistant Staphylococcus aureus isolates among hospitalized patients; a tertiary medical care center experience from Southern Iran. Cogent Medicine.2016;3: 1163768. http://dx.doi.org/10. 1080/ 2331205X.2016.1163768.

17. Namratha KG, Sreeshma P, Subbannayya K, Dinesh $\mathrm{PV}$, Champa H. characterization and antibiogram of Klebsiella spp. isolated from clinical specimen in a rural teaching hospital. Sch. J. App. Med. Sci. 2015; $3(2 \mathrm{E}): 878-883$

18. Manikandan C, Amsath A. Antibiotic susceptibility of bacterial strains isolated from wound infection patients in Pattukkottai, Tamilnadu, India. Int.J.Curr.Microbiol.App.Sci. 2013; 2(6): 195-203.

19. Hosimin K, Prabakaran G. Studies on isolation and characterization of some wound infection causing bacteria. International Journal of Current Advanced Research.2012 Oct; 1(2): 26 - 31 .

\section{How to cite this article?}

Krishnamurthy S, Sajjan AC, G. Swetha, S Shalini. Characterization and resistance pattern of bacterial isolates from pus samples in a tertiary care hospital, Karimnagar. Trop J Path Micro 2016;2(2):49-54.doi: 10.17511/jopm.2016.i02.03 